\title{
FUNDAMENTO CONSTITUCIONAL DE LA LEY DEL SUELO DE GALICIA
}

\author{
POR \\ Jose MARIA DIAZ LEMA
}

\begin{abstract}
SUMARIO: A) La COMPETENCIA eXClusiva de la Comunidad Autonoma en materia de ORDENACION DEL TERRITORIO Y DEL LITORAL, URBANISMO Y VIVIENDA. B) LA ARTICULACIÓN ENTRE EL DERECHO ESTATAL Y. EL AUTONÓMICO. EN ESPECIAL. EL PRINCIPIO DE SUPLETORIEDAD: 1) EI principio de competencia. 2) El principio de prevalencia del Derecho estatal. 3) El principio de supletoriedad: a) Posiciones doctrinales. b) La jurisprudencia del Tribunal Constitucional.-C) EL ACOPLAMIENTO ENTRE LA LEGISLACION ESTATAL Y AUTONOMICA EN MATERIA URBANISTICA. LA «ADECUACION*O «ADAPTACION* DE LA LEY DEL SUELO, CONTENIDO TIPICO DE LA LEGISLACIÓN AUTONOMICA EN MATERIA DE URBANISMO: 1) El contenido de algunas leyes autonómicas en materia de urbanismo. 2) El contenido de la LSG. -D) FUNDAMENTO Y LIMITE, DE LAS COMPETENCIAS ESTATALES EN MATERIA DE SUELO. 1) El problema en la doctrina. 2) Una referencia al Derecho alemán: La Federación ostenta competencia legislativa en materia de suelo. 3) Análisis y comentario de la incidencia de las competencias estatales sobre la ordenación del territorio y urbanismo. Distintos planos. a) Las obras públicas de interés general: ruptura in extremis del planeamiento vigente pero no justifican competencia legislativa estatal. b) ¿Tiene el Estado en algún caso competencia de planificación territorial? c). El fundamento de la competencia legislativa del Estado: artículo 149.1.1 ${ }^{\text {a }}$ de la Constitución. Sus límites. 4) Conclusión: limitada competencia legis/ativa estatal. Sentido de la adaptación de la LSG.
\end{abstract}

\section{A) LA COMPETENCIA EXCLUSIVA DE LA COMUNIDAD AUTONOMA EN MATERIA DE ORDENACION DEL TERRITORIO Y DEL LITORAL, URBANISMO Y VIVIENDA}

La Exposición de Motivos de la Ley del Suelo de Galicia (en adelante, LSG) se inicia con la justificación constitucional de la Ley, señalando que, de acuerdo con el Estatuto de Autonomía gallego, es de la competencia exclusiva de la Comunidad Autónoma la «ordenación del territorio y del litoral, urbanismo y vivienda" (art. 27.3 del Estatuto), por lo que corresponde a la Comunidad Autónoma la competencia legislativa en los términos previstos en el artículo $\mathbf{3 7 . 2}$ del Estatuto.

Para nosotros, es igualmente obligado analizar en primer término la cuestión competencial, esto es, la justificación constitucional de la LSG y los límites dentro de los que se desenvuelve el legislador autonómico. Si después de la Constitución de 1978 en cualquier análisis jurídico hay que tener en cuenta la distribución competencial entre el Estado y las Comunidades Autónomas, porque ésta se ha convertido en un tema medular de la organización del Estado, debemos señalar algunas circunstancias que lo hacen más necesario 
en la LSG: por un lado, la todavía escasa andadura de las Comunidades Autónomas y la necesidad de precisar con rigor sus competencias; por otro, la interferencia frecuente de títulos competenciales del Estado y las Comunidades Autónomas; finalmente, la aprobación de una Ley gallega en materia de suelo y ordenación urbana no es un hecho aislado, sino que responde a una corriente de opinión preocupada por ciertos fenómenos urbanísticos, que se han plasmado en sucesivas Leyes de Comunidades Autónomas: Leyes catalanas de 18 de noviembre de 1981 y 9 de enero de 1984; Leyes de la Comunidad de Madrid de 10 de febrero de 1984 y 30 de mayo de 1984; La LSG objeto de este estudio; así como más recientemente, y sin ánimo exhaustivo, la Ley del Principado de Asturias 3/1987, de 8 de abril, reguladora de la disciplina urbanística; la Ley de Comunidad Autónoma de Canarias 1/1987, de 13 de marzo, reguladora de los Planes Insulares de Ordenación; la Ley de la misma Comunidad Autónoma 5/1987, de 7 de abril, sobre la ordenación urbanística del suelo rústico; la Ley de la Comunidad Autónoma de Baleares 6/1988, de 25 de mayo, por la que se modifica el artículo 228.6 de la Ley del Suelo; la Ley de la misma Comunidad Autónoma 8/1988, de 1 de julio, sobre edificios e instalaciones fuera de ordenación. Todo este movimiento legislativo referido a la ordenación del territorio y al urbanismo puede arrojar mucha luz sobre la real y definitiva aplicación de la Constitución, que ha sido por lo general tachada de ambigua e imprecisa en la distribución de competencias entre el Estado y las Comunidades Autónomas.

\section{B) LA ARTICULACION ENTRE EL DERECHO ESTATAL Y EL AUTO- NOMICO. EN ESPECIAL, EL PRINCIPIO DE SUPLETORIEDAD}

Galicia tiene competencia exclusiva en materia de «ordenación del territorio, urbanismo y vivienda». Como es sabido, el significado del término "exclusivo" tanto en la Constitución como sobre todo en los Estatutos de Autonomía dista mucho de ser unívoco, entendiendo la doctrina que se puede hablar de compentencias exclusivas «plenas» cuando tanto la función legislativa como la ejecutiva se atribuyen al mismo ente; $y$ son, por el contrario "no plenas" las competencias exclusivas en que una función corresponde al Estado (la legislación) y otra función distinta a la Comunidad Autónoma (la ejecución) (1).

En esta materia, la Constitución -art. 148.1.3. a- y el Estatuto de Galicia atribuyen a la Comunidad Autónoma competencia exclusiva

(1) Veáse, sobre esto, Muñoz Machado, S.: Derecho Público de las Comunidades Autónomas I. Civitas. Madrid, 1982, pp. 358 y ss. (hay edic. posterior). Un resumen del concepto de competencia exclusiva de las Comunidades Autónomas, tanto de las posiciones doctrinales como de la jurisprudencia del Tribunal Constitucional, en: MEILAN GIL, J. L.: La ordenación jurídica de las Autonomias. Tecnos. Madrid, 1988, pp. 86 y ss. 
en el primer sentido indicado: es una competencia plena, tanto para dictar Leyes como para ejecutarlas.

Siendo la Comunidad Autónoma competente para legislar en exclusiva, la primera conclusión que se impone es el desplazamiento en esta materia en la legislación estatal (de la Ley del Suelo), de tal modo que, una vez producida la Ley autonómica, decae la Ley estatal. Sin embargo, este efecto tan radical no lo desea la propia.LSG, que en su disposición final 1.a 4 prescribe que: «en todo lo que no resulte modificado por la presente Ley serán de aplicación la Ley del Suelo del Estado y sus actuales disposiciones de desarrollo" (la misma técnica es utilizada por las restantes Leyes autonómicas de que se ha hecho mención: por todas, expresamente la Ley - catalana- de protección de la legalidad urbanística de 18 de noviembre de 1981 , disposición final 1. ${ }^{\mathrm{a}}$ ). Se trata, pues, de una Ley que adapta a las peculiaridades del territorio gallego la legislación urbanística, estableciendo excepciones en una serie de puntos - a veces, muy importantes - a aquélla. Sobre el sentido de la «adaptación» volveremos más adelante. Solo interesa subrayar aquí que en la LSG no se denota la menor intención de producir un ordenamiento urbanístico ex novo, que viniera a sustituir al estatal. Esto obliga a plantearse el significado de las competencias exclusivas atribuidas a las Comunidades Autónomas, y más en concreto la competencia exclusiva o "plena» de legislación, en el marco de la articulación entre el Derecho estatal y el Derecho autonómico.

\section{El principio de competencia}

La relación entre el Ordenamiento estatal y los autonómicos se articula en torno a los siguientes principios: competencia, prevalencia y supletoriedad. Según el primero, la atribución de una materia en exclusiva a una organización territorial determina su competencia legislativa (2). Las normas producidas en el mismo ámbito por la otra organización territorial son inconstitucionales.

Más conflictivo, sin embargo, es el caso de la legislación compartida, en que el Estado dicta la legislación básica o de armonización, que habrá de ser desarrollada por las Comunidades Autónomas. Mientras para unos autores el principio de competencia sigue siendo la explicación adecuada a esta relación, otros por el contrario estiman que aquí entra en juego un criterio de jerarquía

(2) En este punto hay unanimidad en la doctrina. Véanse Muñoz MACHAdo, S., ob. cit., I, pp. 396 y ss. GARCIA DE ENTERRIA: Estudios sobre autonomias territoriales. Civitas. Madrid, 1985 pp. 290, 308, 317. I. DE OTாо: Derecho Constitucional. Sistema de fuentes. Ariel. Barcelona, 1987, pp. 277 y ss. lo denomina principio de especialidad. Garrido FAlLA, F.: «EI desarrollo legislativo de las normas básicas y leyes-marco estatales por las Comunidades Autónomas". RAP 113 (1981), pp. 13 y ss., 18. 
entre normas, que permite a la legislación estatal imponerse a la autonómica (3).

GARCIA DE ENTERRIA describe minuciosamente la relación entre la legislación básica estatal y la legislación autonómica de desarrollo. Según él, el contenido de la norma básica se descompone en tres elementos distintos, a modo de círculos concéntricos: un círculo interior o nuclear, en el que la regulación es íntegramente estatal; un círculo de encuadramiento, que tiene por objeto articular la normativa estatal y la autonómica; y un círculo de suplencia, de carácter facultativo, que cubre las posibles lagunas de la legislación autonómica. Con excepción del último elemento «facultativo», es indudable que los dos primeros deben formar parte de la legislación básica (4).

\section{El principio de prevalencia del Derecho estatal}

Tampoco resulta de fácil interpretación el segundo principio de articulación del Derecho estatal y del autonómico, el de prevalencia del Derecho estatal «en todo lo que no esté atribuido a la exclusiva competencia de las Comunidades Autónomas» (art. 149.3 de la Constitución).

El concepto «prevalencia» del Estado sobre las Comunidades Autónomas puede utilizarse en un sentido amplio o genérico, como expresión del poder superior que obviamente corresponde al Estado, $y$ en tal sentido buena parte de los mecanismos de articulación Estado-Comunidades Autónomas encuentran su apoyo en él. Así, por ejemplo, cuando se dice que la ejecución autonómica de la legislación del Estado es un supuesto de prevalencia estatal, no existiendo

(3) En el primer sentido, MUÑOZ MACHADO, ob. cit., p. 398: no domina una norma sobre otra en razón a su rango, que es el efecto propio de la jerarquía, sino en razón a su contenido, que es lo propio de la competencia. Iguaimente, GARCIA DE ENTERRIA, loc. cit., en nota anterior

En el segundo sentido, especialmente GaRRIDO FA:LA, F., ob. cit., nota anterior, pp. 18 y ss. Cfr. también el sugerente trabajo de GOMEZ-FERRER MORANT, R.: «Relaciones entre Leyes: competencia, jerarquia y función constitucional”, en RAP 113 (1987), pp. 7 y ss.: ni en las relaciones entre las Leyes del Estado (orgánicas/ordinarias), ni entre Leyes del Estado y autonómicas, el principio de competencia da cuenta de la complejidad de los problemas que se plantean.

(4) Garcia de Enterria, loc. cit. (nota anterior), pp. 310 y ss., 317 y ss

Estimamos dudoso, sin embargo, que la relación entre las bases y su desarrollo normativo se fundamente en los principios que señala de preclusión (o cierre), desplazamiento y lo que denomina condición de integración (loc. cit. pp. 317 y ss.). Sobre todo, el primero, el efecto de preclusión - tomado del federalismo alemán-, no explica cabalmente la relación norma básica y norma de desarrollo. Como veremos infra, el efecto preclusión se produce en la llamada concurrencia (normativa) impropia del Derecho Constitucional alemán, porque los Estados, en principio, tienen competencia legislativa por propia iniciativa y sin desarrollar una previa ley federal; sólo si se pone de manifiesto la necesidad de una ley federal que unifique criterios, ésta cierra o excluye la legislación estatal, total o parcialmente. Puestos a buscar a un supuesto similar en nuestra Constitución, habría que pensar más bien, aunque con matices, en la Ley de Armonización del articulo 150.3.

Por el contrario, en la relación leyes básicas-leyes de desarrollo de nuestra Constitución, no es que se quede cerrado a la legislación autonómica nada en el momento de dictar las bases. Las Comunidades Autónomas en nigún momento han podido entrar en la regulación de lo básico. 
siquiera Derecho autonómico (5); o cuando se aplica el mismo concepto a la relación entre la legislación básica y la de desarrollo (6). En estos casos, y en otros que se pueden traer a colación, la propia Constitución regula específicamente la posición superior del Estado y su relación con las Comunidades Autónomas.

Pero el artículo 149.3 de la Constitución no parece dirigido tanto a fijar en el plano de los principios la posición superior del Estado en general, que encontrará su aplicación a lo largo del articulado de la Constitución, cuanto a resolver específicos conflictos normativos entre el Estado y las Comunidades Autónomas que no pueden solucionarse por otras vías. Por tanto, el artículo 149.3 presupone que hay Derecho estatal y autonómico, prevaleciendo el primero.

¿Cuáles son los posibles supuestos conflictivos? No es fácil determinarlos, porque no existe siquiera coincidencia doctrinal sobre la funcionalidad del principio de prevalencia (7). I. DE OTTO estima que la cláusula de prevalencia es de dudosa utilidad en nuestro Derecho, porque está pensada para el caso de competencias legislativas (plenas) concurrentes entre Federación y Estados miembros, sin distinguir entre bases y desarrollo. Esto hace que en un supuesto conflictivo la norma federal invalide la estatal. No existiendo legislación concurrente en nuestro sistema, sino o bien competencias exclusivas o bien la descrita relación Ley de bases-Ley autonómica de desarrollo, la prevalencia del Derecho estatal como algo sustantivo no tiene aplicación. Que el Tribunal Constitucional no haya tenido que acudir a la regla de la prevalencia corrobora su tesis, a juicio del autor citado (8).

Aunque el punto clave que nos interesa dentro de la articulación del Derecho estatal y autonómico es el principio de supletoriedad del

Según el profesor Garcia dE ENTERRIA, «desde ese momento (en que el Estado dicta la legislación básica) esa legislación queda "cerrada", precluida, a la competencia normativa autonómica” (Ibidem, p. 317). Las mismas ideas se repiten al explicar el siguiente efecto, el desplazamiento de la norma autonómica por la estatal (lbidem, p. 318).

A mi juicio, estos efectos pueden producirse en la relación Ley de Armonización-Legislación autonómica. En la relación Leyes básicas-Leyes de desarrollo autonómicas, la Ley básica no cierra ni desplaza la autonómica: simplemente ocupa el lugar primario que le corresponde, y que en ningún momento ha sido propio de la Ley autonómica.

(5) Garcia de Enterria, ob. cit., p. 358 en la misma línea de pensamiento lopez Ramon, $F$. «Planificación territorial» en RAP, 114, p. 144 (y nota 24) aplica la regla de la prevalencia del Derecho estatal para explicar el funcionamiento del artículo 180 de la Ley del Suelo (véase infra). que permite al Estado realizar obras, aun en contra del planeamiento vigente. Baste señalar aqui que el Tribunal Constitucional en la sentencia 56/1986, de 13 de mayo, no acepta el argumento de la prevalencia del Derecho estatal (FJ 2) para resolver este problema (como advierte el propio LOPEZ RAMON, en nota). De todos modos, es evidente que en este caso no está en juego un conflicto con el «Derecho» estatal; un proyecto de obra pública no es Derecho.

(6) Garcia de Enterria: ob. cit., p. 358.

(7) Sobre esto, véase Muñoz MACHADO: ob. cit., pp. 404-05, quien cita varios sistemas federales, llegando a la siguiente conclusión: “A medida que el sistema es más perfecto, la función del principio de prevalencia es menorm.

(8) Véase I. DE OTாо: Derecho Constitucional, cit., p. 281. 
Derecho estatal, debemos detenernos aunque sea brevemente en el principio de prevalencia que ha sido objeto de un amplio tratamiento doctrinal. De hecho es imposible independizar alguno de los principios de articulación Derechos estatal/autonómico (competencia, prevalencia, supletoriedad), porque están estrechamente entrelazados.

En un trabajo muy conocido, I. DE OTTO llega a las siguientes conclusiones: el Estado tiene capacidad normadora general, de la que es manifestación la cláusula de supletoriedad del Derecho estatal «en todo caso"; el Derecho autonómico opera como un Derecho especial, que rompe el Derecho estatal alli donde las Comunidades Autónomas tiene atribuida competencia exclusiva en sentido estricto o pleno; para evitar el deslizamiento hacia la aplicación permanente del Derecho especial autonómico, la regla de prevalencia del Derecho estatal del artículo 149.3 de la Constitución permite a éste interponerse sobre el autonómico, siempre que no se trate de competencias exclusivas de las Comunidades Autónomas (9).

PAREJO ALFONSO, por el contrario, estima que la prevalencia del Derecho estatal se aplica en las competencias compartidas entre el Estado y las Comunidades Autónomas, actuando a modo de norma complementaria del primer principio de articulación: el de competencia. Siendo el efecto de la prevalencia del desplazamiento del legislador autonómico (10).

GARCIA DE ENTERRIA, apurando el análisis anterior, estima que la prevalencia del Derecho estatal no es una regla de distribución de competencias, de modo que desaloje a las Comunidades Autónomas de la suyas, sino que resuelve supuestos de colisión o conflicto. Su efecto es desplazar en la aplicación concreta a la norma autonómica, aunque sin llegar a derogarla.

Según esto, el campo de aplicación del principio de prevalencia sería doble: 1. . lo que GARCIA DE ENTERRIA denomina cooperación e interferencia entre Ordenamientos, en el que incluye la relación entre las bases del Estado y el desarrollo autonómico, o la ejecución autonómica de la legislación estatal. Como se ha señalado, esto supone una concepción muy amplia de la prevalencia, que en la sistemática constitucional aparece como un criterio residual (para resolver conflictos que los otros mecanismos de la Constitución no atienden). Se puede aceptar en un sentido genérico, como un criterio revelador de la superior posición del Estado, que encuentra distintas manifestaciones en el texto constitucional.

El segundo supuesto al que aplica el profesor GARCIA DE ENTERRIA la regla de la prevalencia, entendemos que es el específico del

(9) DE Опо, I: «La prevalencia del Derecho estatal sobre el Derecho regional». Revista Española de Derecho Constitucional, núm. 2 (1981). p. 71 y 75 y ss.

(10) Parejo Alfonso, L.: La prevalencia del Derecho estatal sobre el regional. Centro de Estudios Constitucionales. Madrid, 1981, pp. 91 y ss., 101, 104, 112, 115. 
artículo 149.3 de la Constitución: es el caso de la llamada superposición de títulos competenciales, cuando el ejercicio de una competencia autonómica dificulta el ejercicio de una competencia estatal: en este caso, prima ésta (11). Se trataría, en definitiva, de resolver aquellos conflictos de interferencia de títulos competenciales, que se producen sobre todo cuando el Derecho autonómico en una materia de su competencia exclusiva choca con el Derecho estatal legítimamente producido en una materia distinta (12), (13).

\section{El principio de supletoriedad}

El tercer principio de articulación del Derecho estatal y el autonómico es el de supletoriedad. "En todo caso", dice el artículo 149.3 de la Constitución, el Derecho estatal es supletorio del Derecho autonómico.

Quizá por su carácter residual la supletoriedad del Derecho estatal no ha sido muy estudiada por la doctrina, e incluso la jurisprudencia del Tribunal Constitucional en las repetidas ocasiones en que se ha pronunciado sobre el mismo, lo ha hecho de una forma rotunda, sin los matices que probablemente requiera.

Aqui debe ser objeto de atención, porque la LSG - según hemos visto, así como las restantes Leyes autonómicas-declara aplicable el Derecho estatal - LS y sus Reglamentos- en todo lo que no resulte modificado por la LSG - disposición final 1 . $^{\mathrm{a}}$. 3-, lo que no es sino manifestación del principio de supletoriedad del citado artículo 149.3 de la Constitución, que a su vez recoge el Estatuto de Autonomía de Galicia (Ley Orgánica 1/1981, de 6 de abril), artículo

(11) Garcia de Enterria, E.: Estudios sobre autonomías territoriales. Cit., pp. 352 y ss., 362.

(12) En el ámbito del Derecho alemán, del que nuestra Constitución ha incorporado muchos elementos y que suele servir de contraste para su análisis, la funcionalidad del principio de prevalencia ha sido muy discutida (Cfr. I. DE OTTO: La prevalencia..., ob. cit., pp. 59 y ss. para demostrar que esta regla propia de los Estados federales no puede tener aplicación en nuestro sistema, que no es federal, sino regional).

No obstante, algunas conclusiones de la doctrina alemana sobre el artículo 31 de la Ley Fundamental (que contiene el principio de ruptura del Derecho estatal por el federal) pueden sernos útiles: $1 .^{a} \mathrm{Ha}$ de tratarse de conflictos entre normas. $2 .^{\circ}$ Es una regla de colisión, no de atribución competencial. $3 .^{a}$ Es una norma de principio que puede ser contradicha o desarrollada por otras disposiciones especiales de la Ley Fundamental. Asi, la distribución competencial de los artículos 70 y siguientes de la Ley Fundamental constituye una concreción o norma especial del artículo 31. El alcance del efecto es discutido: para unos, en el mismo sentido que GARCIA DE ENTERRIA (véase supra) sólo se produce un reiteramiento del Derecho estatal, o no aplicación al caso concreto, mientras que otros estiman que se produce la nulidad del Derecho estatal, que parece la tesis más realista (asi, GUBELt, M., en el comentario al artículo 31, en: GrundgesetzKommentar (ed. I. v. Münich). 2. Auflage. Münich, 1983, pp. 299 y ss.

(13) Cfr. igualmente MEILAN GIL: La ordenación jurídica, ob. cit., pp. 81 y ss.: la prevalencia estatal es residual y sirve para resolver conflictos: no es norma de competencia, como pretendía la non nata LOAPA. 
38.2, en los siguientes términos: «A falta de Derecho propio de Galicia, será de aplicación supletoria el Derecho del Estado» (14).

Como veremos infra, el gran problema que se plantea en la relación entre la legislación estatal del suelo y las Leyes autonómicas es el de saber hasta dónde el Derecho autonómico puede arrinconar o colocar en una posición supletoria al Derecho estatal. No obstante la aparente marginalidad del principio de supletoriedad, se esconde bajo él una de las claves decisivas para entender las relaciones entre el Derecho estatal y el autonómico, y con ello la configuración misma del tipo de Estado. Así lo vio tempranamente I. DE OTTO, en el trabajo citado supra (15), cuando señalaba que «la atribución de una competencia a las comunidades Autónomas no significa la paralela privación de esa misma competencia para el Estado" (16). La única consecuencia es que el Derecho estatal pasa a ser supletorio, lo cual es, según este autor, una manifestación de que el Estado configurado en la Constitución de 1978 no es federal, sino regional (17).

Varios años después, en un estudio al que nos referiremos ampliamente infra, BALZA AGUILERA/DE PABLO CONTRERAS (18) estiman que, siendo la norma autonómica expresión de una política propia de la Comunidad Autónoma que puede ser diversa o incluso contradictoria con la estatal, no sería procedente el recurso directo, ilimitado y absoluto al Derecho estatal con carácter supletorio (19). Lo que se teme y critica es que la regla de la supletoriedad sirva de cauce para debilitar la posición legislativa de las Comunidades Autónomas, enfrentadas a una omnipresente legislación estatal.

Pero la regla de la supletoriedad del Derecho estatal no es sólo aparentemente marginal. Es también «paradójica», como la califica MUÑOZ MACHADO (20). Parece, en efecto, un cuerpo extraño dentro de la articulación global entre el Derecho estatal y el Derecho autonómico. Si, como se entiende sin excepción, la atribución de facultades legislativas al Estado o a las Comunidades Autónomas se rige, ante tcdo y en primer término, por el principio de competencia, de modo que en las competencias exclusivas de las Comunidades Autónomas éstas pueden desplazar plenamente el Derecho estatal, es legítimo

(14) Contamos ya con dos exposiciones sistemáticas del Derecho propio de Galicia. Cores Trasmonte, B.: Decreto autonómico de Galicia. Xerais de Galicia. Vigo, 1987. Y MeILAn Gil, J. L. y Rodriguez Arana, J.: Decreto estatutario galego. Ed. del Parlamento de Galicia, 1988.

(15) La prevalencia del Derecho estatal, cit.

(16) Ibidem, p. 75.

(17) Ibidem, p. 72

(18) El Derecho estatal como supletorio del Derecho propio de las Comunidades Autónomas REDA, 55 (1987), 429.

(19) Ibidem, p. 429

(20) En: Derecho Público de las Comunidades Autónomas. I. Cit., p. 409 
preguntarse por el extraño y oscuro papel que la Constitución asigna al principio de supletoriedad (21).

Hechas estas advertencias, pasemos a examinar las distintas posturas doctrinales sobre la supletoriedad del Derecho estatal, así como la jurisprudencia del Tribunal Constitucional. Sólo en este marco tendrá sentido plantearse la relación entre la LSG y la legislación estatal sobre el suelo y ordenación urbana.

\section{a) Posiciones doctrinales.}

Señalemos, en primer lugar, la que se puede denominar concepción expansiva del principio de supletoriedad, cuyo más claro exponente es I. DE OTTO en el artículo anteriormente citado. Parte este autor, como se ha visto, de una competencia normadora general del Estado, que es a su vez trasunto de su configuración como un Estado regional. Esto significa que puede dictar normas en cualquier materia y en cualquier momento, aun en materias de competencia exclusiva de las Comunidades Autónomas. A las dos cuestiones que aquí se plantean, esto es, si puede el Estado dictar normas en materias de competencia exclusiva de las Comunidades Autónomas, y si puede hacerlo incluso después de haber legislado aquéllas, responde afirmativamente. Es evidente que en tales circunstancias las llamadas competencias exclusivas de las Comunidades Autónomas son de hecho concurrentes, gracias precisamente al juego que hace el principio de supletoriedad. Ahora bien, estas normas estatales en materia de competencia exclusiva de las Comunidades Autónomas tienen únicamente valor supletorio. Importa retener la conclusión final de esta argumentación, porque aparece con frecuencia en la jurisprudencia constitucional, y que se resume en el binomio vigencia/validez: el Derecho estatal puede perder paulatinamente su vigencia al ser desplazado por el Derecho autonómico en sus competencias exclusivas, pero nunca su validez. Siempre será válido, aunque su valor será supletorio. La expresión uen todo caso" del artículo 149.3 de la Constitución es interpretada aquí del modo más amplio posible (22).

(21) En la Ley Fundamental alemana, por poner un modelo de Estado federal conocido y asentado, no existe tal regla de supletoriedad. En cierto modo la lógica de un sistema federal lleva justamente a la posición contraria: salvo en las materias que los artículos 70 y siguientes atribuyen expresamente competencia legislativa a la Federación -que son, desde luego, amplisimas - en todo lo demás son los Estados competentes, en virtud del principio federal del sistema contenido en el articulo 30 .

Cfr. en el mismo sentido Muñoz Machado, S.: Derecho Público, I, cit., p. 411, a propósito del federalismo estadounidense; aunque también cita el federalismo suizo, en que sucede justamente lo contrario: en materia de Derecho privado la regulación cantonal es complementada por la federal.

(22) Cfr. De Oто, I.: La prevalencia del Derecho estatal, ob. cit., pp. 72, 75. Igualmente en su obra posterior, Derecho constitucional, cit., p. 282: el Estado puede seguir dictando normas. aunque tengan un valor supletorio. 
Esta tesis encaja en el tenor literal del artículo 149.3 («en todo caso"), pero no deja de ser contradictoria con el conjunto del sistema y puede llevar a resultados absurdos. Es contradictoria, como ya se ha señalado, porque deja en el aire el principio rector de la competencia y puede llevar al absurdo que el Estado siga dictando - con valor supletorio- normas en materias en que las Comunidades Autónomas hayan hecho un uso pleno de sus facultades legislativas (exclusivas). Esa legislación estatal condenada al vacío -o a la perturbación- no puede ser aceptada, porque además ni siquiera tendría que ser armónica con la legislación autonómica, a la que supuestamente va a suplir.

Muy distinta es la posición de S. MUÑOZ MACHADO, expuesta sobre todo en su obra "Derecho Público de las Comunidades Autónomas», tomo I. Ante todo, niega que la supletoriedad del Derecho estatal está vinculada a la competencia universal del Estado (como vimos, la tesis central de I. DE OTTO), atribuyéndole más bien un significado coyuntural, fruto del peculiar proceso de descentralización política que opera la Constitución de 1978. Así, indica tres argumentos que justifican el mantenimiento del Derecho estatal: la existencia de este Derecho previo a los Estatutos de Autonomía, que sólo paulatinamente será desplazado; la heterogeneidad de las competencias de las Comunidades Autónomas, que permite al Estado esgrimir para partes del territorio títulos competenciales que ha perdido en relación con otras; en último lugar, el Ordenamiento estatal sería más completo, pudiendo ofrecer unidad, sistematicidad y coherencia al Ordenamiento de las Comunidades Autónomas. La legislación autonómica tendría siempre huecos, intersticios, vanos, que deben rellenarse con el Derecho estatal.

Se habrá observado que, mientras que los dos primeros argumentos son exponentes del carácter coyuntural del Derecho estatal, el tercero apunta a su vigencia indefinida, pero únicamente porque en el Derecho estatal "será posible encontrar principios jurídicos complementarios de las regulaciones sectoriales que formulen las Comunidades Autónomas» (23). Pero la supletoriedad del artículo 149.3, tal como la concibe este autor, es más debilitada no sólo por razón de su ámbito, material y temporal. También lo es por sus efectos. No procede, según él, la apelación inmediata al Derecho del Estado, sino que «debe ensayarse primeramente una integración de la laguna acudiendo a las reglas propias del Derecho autonómico» (24). Se convierte, así, en una supletoriedad de segundo grado.

En último término, se plantea la posibilidad de que el Estado siga emitiendo normas válidas después de la entrada en vigor de los

(23) Véase Muñoz Machado, S.: Derecho Público, ob cit., p. 411.

(24) Ibidem, p. 412. 
Estatutos de Autonomía. Cuestión que contesta afirmativamente, pero con un límite muy preciso: hasta que las Comunidades Autónomas hayan hecho uso de su competencia. Hay, pues, una prorrogatio de la potestad legislativa estatal, que termina en el momento en que aparece la legislación autonómica (25). Lo cual es coherente con el carácter central que el principio de competencia tiene en el entero sistema autonómico.

En un trabajo reciente BALZA AgUILERA/De PABLo Contreras (26) desarrollan y amplian las tesis de MUÑOz MACHADO, llegando a resultados que reseñamos a continuación. Ante todo, distinguen dentro de lo que se conoce como supletoriedad del Derecho estatal frente al autonómico tres situaciones distintas: la supletoriedad entre Ordenamientos, la supletoriedad entre normas, y aquellos supuestos de remisión a la norma estatal para evitar un vacío normativo. Sólo la primera encajaría dentro de la regla de la supletoriedad del artículo 149.3 de la Constitución. Pero veamos con más precisión a qué se refieren en cada caso.

La supletoriedad entre Ordenamientos, la del artículo 149.3 de la Constitución, tiene un significado estructural. Si el Estado se ha reservado en el artículo 149.1 de la Constitución las competencias más importantes, las estructuras del Ordenamiento jurídico, es lógico que la legislación autonómica tenga que acudir al Derecho estatal. Así - dicen-, una Comunidad Autónoma podrá regular una materia educativa, supuesta su competencia, pero para interpretar dicha norma deberá acudir al artículo 3‥1 del Código Civil (27). Esta supletoriedad, por tanto, no implica, tal como lo entendía I. DE OTTO, una competencia normadora general del Estado, sino que la legislación estatal termina allí donde terminan sus competencias. Solo dentro del principio de competencia adquiere su sentido el principio de supletoriedad del artículo 149.3 de la Constitución (28). En suma, la relación entre Derecho estatal y autonómico que dimana del principio de supletoriedad no es la propia del Derecho general-Derecho especial (I. DE OTTO), sino la relación entre Derecho común y Derecho particular, esto es, la misma situación en que se encuentran el Código Civil y los Derechos forales (29).

Un supuesto distinto al anterior es el que denominan supletoriedad entre normas, en que la aplicación del Derecho estatal no deviene de la regla de la supletoriedad del artículo 149.3 de la Constitución, sino de la disposición del Código Civil sobre analogía (artículo 4.1). Para ello, es preciso, ante todo, que se produzca un vacío en la norma

(25) Ibidem, pp. 414-415.

(26) El derecho estatal como supletorio, ob cit., pp. 381 y ss.

(27) Véase Muñoz Machado, S.: El Derecho estatal como supletorio, ob cit., p. 416.

(28) Ibidem, p. 415.

(29) Ibidem, p. 417. 
autonómica, que se deducirá de una interpretación sistemática de la misma. Debe existir «identidad de razón» entre ambas normas (estatal y autonómica). Por ello, no se puede aceptar la aplicación de Derecho estatal, que violente y contradiga los principios de Derecho autonómico (de la concreta norma autonómica, que no es más que expresión de la política propia de la Comunidad Autónoma) (30).

El tercer supuesto que analizan es el que podríamos denominar aplicación coyuntural del Derecho estatal. También aquí éste rige por una razón distinta al principio de supletoriedad del artículo 149.3 de la Constitución; en concreto para evitar una peligrosa situación de vacío normativo, que se produciría como consecuencia de la puesta en marcha del proceso autonómico. En esta remisión coyuntural al Derecho estatal encajan lo que denominan "supletoriedad inicial», esto es, la situación anterior al ejercicio de sus facultades normativas por las Comunidades Autónomas; o las disfunciones que se pueden producir como consecuencia de la heterogeneidad de competencias estatutarias (que a la postre ha resultado ser muy pequeña, por lo que el margen de la potestad normadora estatal es mínimo); o, en fin, la posibilidad de que no todo el territorio nacional se estructurara en Comunidades Autónomas, circunstancia que tampoco se ha producido (31).

Ha de señalarse que la doctrina viene estimando que la regla de la supletoriedad se justifica precisamente por estas tres circunstancias (32), que en el trabajo que venimos comentando tienen una trascendencia menor - porque los hechos posteriores a la Constitución así lo han querido-, y sobre todo sitúan este problema de la remisión al Derecho estatal por no existencia de Derecho autonómico de tipo coyuntural fuera de la regla de la supletoriedad del artículo 149.3 de la Constitución.

El resultado final de la tesis de BALza AgUILERA/De PABLo CONTRERAS es que es un contrasentido sostener la competencia del Estado para seguir dictando Derecho en el futuro en competencias exclusivas de las Comunidades Autónomas, una vez que éstas han dictado la correspondiente legislación. «No cabe crear Derecho para que sea sólo supletorio de otro Derecho» (33). Por tanto, el Derecho estatal, en estos casos, dejará de ser aplicable, incluso como supletorio, viéndose íntegramente sustituido por el autonómico (34).

Esto significa que para los autores citados, la expresión «en todo caso» del artículo 149.3, que implica una vigencia constante del Derecho estatal, sólo puede ser atribuida a lo que denominan

(30) Ibidem, pp. 419,426 y ss.

(31) El Derecho estatal como supletorio, ob cit., p. 420

(32) Por todos, recientemente, MEILAN GIL, J. L.: La ordenación juridica, cit. p. 157

(33) Ibidem (notas precedentes), p. 430.

(34) Ibidem, p. 431. 
supletoriedad estructural o entre Ordenamientos, no a los restantes supuestos supra analizados. Esa posible llamada continua al Derecho estatal sólo cabe para rellenar con los principios estructurales del global sistema jurídico el particular Derecho autonómico. Fuera de aquí, y existiendo legislación autonómica en materias de competencia exclusiva, está vedado al Estado legislar.

La postura de MEILÁN GIL en el libro anteriormente citado (en nota) pretende conciliar los distintos puntos que aquí se dan cita. No considera, de entrada, tan transitoria y coyuntural la regla de la supletoriedad, como lo demuestra sobre todo el que ésta sirva para cubrir el hueco de los distintos ámbitos competenciales autonómicos. La supletoriedad del Derecho estatal no se detiene, por tanto, en las competencias exclusivas de las Comunidades Autónomas, como pretenden BALZA AGUILERA/DE PABLO CONTRERAS. Ahora bien, estima MEILÁN que la supletoriedad del Derecho estatal no puede convertirse en un «medio espúreo» de redistribución de competencias (mejor cabría decir, de privación solapada de competencias a las Comunidades autónomas), por lo que defiende la autointegración del Derecho autonómico en sus competencias exclusivas, en razón de la prevalencia del Derecho autonómico en estos casos. Una «expeditiva heterointegración» del Derecho autonómico en el Derecho estatal «volatilizaría» las competencias autonómicas exclusivas (35).

Al final, la articulación entre Derecho estatal y autonómico vendría a pivotar sobre un juego de prevalencias: del Derecho autonómico sobre el estatal en las competencias exclusivas de las Comunidades Autónomas; y viceversa, en los demás casos, y siempre que las Comunidades Autónomas tengan atribuidas facultades legislativas.

\section{b) La jurisprudencia del Tribunal Constitucional.}

En la jurisprudencia del Tribunal Constitucional la regla de la supletoriedad del Derecho estatal aparece con tanta frecuencia como uniformidad. Son, en efecto, numerosas las decisiones del Tribunal en que trae a colación dicha regla, lo que demuestra que, si la comparamos con la práctica ausencia de referencias a la prevalencia, en la supletoriedad del Derecho estatal radica efectivamente una de las claves para entender la articulación del Derecho estatal y el autonómico. Sorprende, sin embargo, la uniformidad del Tribunal en la interpretación que deba darse a esta regla: no hay prácticamente variación desde las decisiones de 1981 hasta la actualidad.

Se ocupó ya del tema en la STC 5/1981, de 13 de febrero (Estatuto de Centros Escolares), en cuyos fundamentos juridicos 23 y

(35) MEILAN GiL: La ordenación juridica... cit., pp. 157 y ss. 
27 estima que, aun teniendo determinadas competencias en materia de enseñanza las Comunidades Autónomas vasca y catalana, eso no significa la derogación de ciertos preceptos de la Ley Orgánica de 19 de junio de 1980, de Centros Escolares, sino sólo su «modificación»o sustitución por la legislación autonómica correspondiente, pasando el Derecho estatal a ser supletorio (36).

Cabría pensar que la rigidez de la postura del Tribunal estuviera relacionada con la materia objeto del recurso - un derecho fundamental, la educación-, en que el margen de la legislación autonómica tiene que ser forzosamente reducido. Pero la doctrina del Tribunal se ha mantenido en los mismos términos en otros asuntos, en los que la competencia legislativa autonómica (incluso con carácter exclusivo) no se pone en duda. Así, en la STC 69/1982, de 23 de noviembre, después de reconocer que la Comunidad Autónoma (Cataluña) tiene competencia exclusiva sobre espacios naturales protegidos, añade que el Derecho estatal será en todo caso supletorio en Cataluña. Aunque no deja de apreciar que la remisión al Derecho estatal será menor, a medida que se consolide el Derecho autonómico en este campo. Pero nunca desaparecerá la supletoriedad del Derecho estatal.

La STC 84/1982, de 23 de diciembre, aporta algo nuevo, porque introduce el tema de la supletoriedad también en la relación entre el Derecho básico estatal y las normas autonómicas de desarrollo. Aparentemente, en esta relación entre ambos Derechos la función del Estado debiera agotarse en dictar la legislación básica. Pues bien, el Tribunal Constitucional estima en esta sentencia -cuyo objeto era la distribución competencial en el régimen local-que, si el Estado además de disposiciones básicas establece otras (de desarrollo), éstas pasan a tener un valor supletorio, si llegan a ser sustituidas por la legislación autonómica (37).

En la STC 95/1986, de 10 de julio, el Tribunal Constitucional vuelve a aplicar la regla de la supletoriedad. En esta ocasión se revelan, sin embargo, los límites de la misma. Después de declarar el Tribunal que ciertos preceptos del Decreto de 22 de junio de 1983 sobre ayudas a jóvenes agricultores relativos a la ejecución — gestión y control- de las mismas son inconstitucionales, porque despojan a la Comunidad Autónoma de Cataluña de su competencia, en el último

(36) Esta sentencia tiene un gran interés, porque ha condicionado de forma duradera la posición del Tribunal. Por lo demás, el trabajo antes citado de I. DE OTTO, La prevalencia del Derecho estatal, p. 74, se refiere a ella, y sin duda ha inspirado su comprensión de la regla de la supletoriedad, en relación con los principios de prevalencia y sobre todo de competencia.

(37) Esto viene a ser el acírculo de suplencia» de que habla GARCIA DE ENTERRIA, como un contenido facultativo de la legislación básica (véase supra). 
fundamento jurídico estima que eso no implica la nulidad de dichos preceptos, sino su no aplicación directa en Cataluña (pasan a tener rango supletorio).

Finalmente, los autos 12/1987, de 13 de enero, y 934/1987, de 21 de julio; tocan, una vez más el tema de la supletoriedad del Derecho estatal, aquí con la finalidad de aplicar la norma del Estado mientras esté en suspenso la norma autonómica, como consecuencia de la interposición de un conflicto positivo de competencias (art. 161.2 de la Constitución).

En una sintesis de la jurisprudencia del Tribunal Constitucional sobre este tema puede decirse que tiene una concepción expansiva de la supletoriedad del Derecho estatal. Esto se advierte ante la expresión "en todo caso», punto crucial de interpretación del precepto. Para el Tribunal, significa tanto una «permanencia» en el tiempo del Derecho estatal (frente a la coyunturalidad o puesta en marcha del sistema autonómico, que se ha esgrimido tantas veces) (fundamento jurídico 2, in fine, de la sentencia citada 69/1982); significa también que el ámbito material a que puede extenderse el Derecho estatal con carácter supletorio no tiene límites: alcanza a las competencias exclusivas de las Comunidades Autónomas-que parece su campo específico-, pero también a la legislación autonómica de desarrollo de la legislación estatal (sentencia 84/1982, citada supra); por último, la expansividad de la supletoriedad estatal tampoco conoce límites en lo que se refiere a los supuestos que pueden caer bajo ella. No hay en la jurisprudencia del Tribunal, por ejemplo, rastro alguno de las distinciones que han hecho algunos autores (véase supra), entre supletoriedad estructural o entre Ordenamientos, supletoriedad entre normas concretas y simple remisión en bloque al Derecho estatal, a falta de regulación autonómica. Ya vimos que el resultado de tales distinciones consiste fundamentalmente en aplicar las graves consecuencias de la supletoriedad estatal en ciertos casos (supletoriedad estructural). Pero éste no es el criterio que guía al Tribunal, que extiende dicha regla a cualquier caso, con independencia de la causa concreta que haya provocado el vacío normativo (así, el auto citado 934/1987, fundamento jurídico 3: el Derecho estatal será supletorio cuando no haya regla jurídica aplicable al supuesto de hecho, y no solamente cuando la Comunidad Autónoma no ha hecho uso de su competencia normativa).

El efecto de la supletoriedad estatal ha sido descrito acudiento al juego de la validez/vigencia de las normas. El Derecho estatal sería siempre válido, aunque perdería paulatinamente su vigericia a medida que las Comunidades Autónomas legislaran en sus compe- 
tencias exclusivas (38). Toda la jurisprudencia del Tribunal Constitucional recoge este planteamiento, que podría resumirse en que el Derecho autonómico va progresivamente arriconando al Derecho estatal. Como dice la sentencia 69/1982 antes citada, si la Comunidad catalana dicta una Ley de espacios naturales protegidos, la posibilidad de acudir al Derecho estatal será «obviamente menor», aunque nunca desaparezca del todo.

Ahora bien, este resultado no deja de ser ficticio, encubriendo en el fondo una pretensión irreal. Basta para comprobarlo que volvamos nuevamente a la STC 95/1986 antes citada, que aplicando al pie de la letra la doctrina del Tribunal, estima que los preceptos del Decreto de 22 de junio de 1983 que invaden la competencia autonómica no son de aplicación directa, sino supletoria (y, por tanto, válidos). Esto evidentemente es un juego de palabras. Dichos preceptos son sencillamente nulos, y no pueden ser aplicados de forma directa ni supletoria. Esta especie de «hibernación» del Derecho estatal a que conduce la aplicación de la distinción validez/vigencia a este problema no resuelve nada, y es probable que pueda crear problemas de seguridad jurídica.

En definitiva, la regla de la supletoriedad del Derecho estatal, tal como la entiende el Tribunal Constitucional, en un sentido expansivo, tiene una base muy amplia, pero en su eficacia es quebradiza. Puede rodear por todas partes al Derecho autonómico, pero allí donde éste ostenta competencias legislativas desplaza pura y simplemente al Derecho estatal.

Cabe preguntarse por último si la concepción del Tribunal Constitucional de la supletoriedad del Derecho estatal incluye la posibilidad de que el Estado legisle después de lo que hayan hecho las Comunidades Autónomas (en sus competencias exclusivas). Ya hemos visto cómo para algunos autores esto no ofrece duda, por ostentar el Estado una potestad normadora general, que no está congelada para el futuro (39). El Tribunal Constitucional no se ha referido en ningún momento a esta posibilidad, aunque cabe inferir de todo su planteamiento que ésta debiera ser su posición.

C) EL ACOPLAMIENTO ENTRE LA LEGISLACION ESTATAL Y AUTONOMICA EN MATERIA URBANISTICA. LA «ADECUACION»O «ADAPTACION»DE LA LEY DEL SUELO, CONTENIDO TIPICO DE LA LEGISLACION AUTONOMIA EN MATERIA DE URBANISMO

El difícil acoplamiento de la legislación estatal y la autonómica que revela el apartado precedente no podía dejar de aparecer en la

(38) Este es el punto central del análisis de I. DE Orro, como hemos visto supra (Prevalencia del Derecho estatal, pp. 74 y ss.), apoyándose en la STC 5/1981, de 13 de febrero.

(39) I. de OTto: Prevalencia..., cit. p. 75. 
legislación que las distintas Comunidades Autónomas han dictado en materia de urbanismo. Por tratarse de un problema común de interpretación de una misma competencia exclusiva, vamos a referirnos en primer lugar a la Ley de 18 de noviembre de 1981, de protección de la legalidad urbanística en Cataluña, la primera en su género. Dice su Exposición de Motivos (I) que por ser reciente la asunción de la competencia urbanística, "parece conveniente optar por su desarrollo y aplicación y no por su sustitución» (de la Ley de Suelo -en adelante, LS-).

Como señala CARCELleR FeRnÁndez, la primera cuestión que se planteó en la elaboración de esta Ley fue si procedía aprobar una Ley de urbanismo para Cataluña o si era mejor limitarse a regular los aspectos que de manera urgente reclamaban una normativa, más que nueva complementaria (40). En otras palabras, estaba en discusión el significado de las competencias exclusivas de las Comunidades Autónomas en el plano legislativo, que se puede resumir en la alternativa sustitución-supletoriedad de la legislación estatal. La primera opción implica el desplazamiento de la Ley estatal, que ve ocupar su lugar por la Ley autonómica. La segunda, por el contrario, supone que la Ley autonómica establece excepciones a la Ley estatal en cuestiones determinadas, manteniéndose ésta en vigor en todo lo demás.

Esta última opción ha sido la finalmente adoptada en la Ley catalana, si bien los parlamentarios catalanes han hecho especial hincapié en que esto no implica renuncia implícita ni explícita a la competencia legislativa autonómica (41). Indirectamente, aunque de forma bien expresiva, late aquí una concepción de la legislación autonómica como plenamente desplazante o sustitutiva de la legislación estatal en materia de urbanismo, de tal modo que sólo por renuncia del Parlamento autonómico - basada en las razones de oportunidad aludidas - tiene cabida la LS estatal.

La dialéctica sustitución-supletoriedad de la LS se observa en la LSG, en cuya Exposición de Motivos (I) se lee lo siguiente:

"En el ejercicio de esta facultad (legislativa) no se propone, sin embargo, la.sustitución en bloque del régimen general establecido por la LS, respetándose el esquema de ordenación contenido en la legislación estatal, modificando y desarrollando aquellos aspectos concretos, en los que, por la generalidad y abstracción de los preceptos, se presentan dificultades de aplicación a un territorio como el gallego con peculiaridades muy singulares con respecto al resto del territorio nacional.»

(40) En «Génesis y aprobación de la Ley de Cataluña 9/1981, de 18 de noviembre, sobre protección de la legalidad urbanisticam, en $R D U, 77$ (1982), pp. 32 y ss.

(41) Ibidem, p. 33, en nota. 
En consecuencia - añade-, la LS se configura como normativa supletoria de lo no previsto en la LSG.

Aunque la cuestión de fondo subsiste - sustitución-supletoriedad del Derecho estatal en materia de urbanismo-, el tono empleado en el párrafo transcrito denota una visión del problema más moderada y realista, como tendremos ocasión de comprobar infra, en la que, sin renunciar al ejercicio de las competencias autonómicas, no se olvida que en la legislación del suelo estatal puede haber disposiciones que exceden el ámbito de actuación de las Comunidades Autónomas.

\section{El contenido de algunas Leyes autonómicas en materia de urbanismo}

Para no caer en un excesivo formalismo, vamos a hacer un repaso somero del contenido de algunas Leyes autonómicas en materia de urbanismo. Así se podrá apreciar en qué medida la legislación autonómica se separa de la estatal, y qué finalidades persigue en cada caso.

En la ley catalana de 18 de noviembre de 1981, de protección de la legalidad urbanística, «se trata -como dice la Exposición de Motivos (I)- de completar la legislación (la LS) para perfeccionar y hacer más eficaces los mecanismos que ya recoge...». Establece disposiciones más severas para las urbanizaciones de iniciativa particular, refuerza el Derecho sancionatorio administrativo en este terreno, con mecanismos que luego pasarán a las demás Leyes autonómicas, y finalmente, en la misma línea, da entrada de una manera decidida al Registro de la Propiedad como apoyo a la protección de la legalidad urbanística. No puede decirse que haya en esta Ley ni una sola excepción a los principios básicos de la legislación estatal; al contrario, refuerza y actualiza los sistemas de protección de aquélla.

Lo mismo puede decirse de la Ley catalana de 9 de enero de 1984, de medidas de adecuación del Ordenamiento urbanístico de Cataluña. El concepto «adecuación» es bien expresivo del acoplamiento entre el Derecho autonómico y el Derecho estatal en esta materia. Lejos ya de la declaración contenida en la Exposición de Motivos de la Ley de 1981 (ya citada), esta Ley catalana de 1984 trata de adecuar el Ordenamiento estatal a las exigencias de la ordenación urbana en Cataluña. "Adecuación», "adaptación», son los términos que se emplean, «respetando el marco urbanístico general». Como más adelante veremos en la LSG, el legislador catalán encuentra hechos diferenciales que justifican un tratamiento urbanístico distinto del general: el relieve, el tamaño de los Municipios, las características de las propiedad fundiaria, la dimensión de sus agentes urbanísticos y las peculiaridades históricas, industriales o turísticas de sus asenta- 
mientos. El resultado es un conjunto de disposiciones sobre planeamiento, suelo urbanizable - con creación de los llamados «sectores de urbanización prioritaria»-, etc. La impresión que se desprende de la lectura de esta Ley, al igual que de la de su hermana de 1981, no es otra que una concreción y un perfeccionamiento de la legislación estatal, manteniendo plenamente los instrumentos conceptuales de ésta.

Esto mismo sucede en la Ley de la Comunidad de Madrid de 10 de febrero de 1984, sobre medidas de disciplina urbanística. Su objeto es una regulación más estricta de las urbanizaciones de iniciativa particular; complementariamente, normas más rígidas para evitar la urbanización en suelo no urbanizable, y un conjunto de disposiciones para el control de la edificación y el uso del suelo.

La Ley de Asturias 3/1987, de 8 de abril, mantiene la misma idea de adaptación y de complemento, pero no de reemplazo de la LS, como sucede en la LSG; en la Ley canaria 1/1987, de 13 de marzo, aparece otra vez el concepto de adaptación, aunque aquí vinculado a los instrumentos de planeamiento que mejor se ajusten a la singularidad de las islas. El resultado es un híbrido entre la planificación urbanística y la territorial: el Plan Insular. La Ley canaria $5 / 1987$, de 7 de abril, contiene una ordenación más detallada del suelo rústico, aunque dentro de las coordenadas de la legislación estatal. La Ley de Baleares $6 / 1988$, de 25 de mayo deroga el artículo 228.6 de la LS, incrementando las cuantías de las sanciones y atribuyendo a las distintas autoridads autonómicas y locales la competencia, en función de la cuantía. La Ley de Baleares 8/1988, de 1 de julio, deroga el artículo 60 de la LS sobre edificios fuera de ordenación, y en su lugar establece un régimen más riguroso y sometido a control.

\section{El contenido de la LSG}

Para la ordenación urbanística de Galicia, el legislador gallego se encontraba con un problema similar al descrito para las otras Comunidades Autónomas. De la lectura del Diario de Sesiones del Parlamento se desprende una sistemática insatisfacción ante el proceso urbanizador en la región derivado de la LS de 1976. Ante todo, se insiste en la inaplicación de la legislación estatal, muy centrada como es sabido en la existencia previa de un instrumento de planeamiento. La generalizada carencia de los mismos ha determinado, probablemente con mayor intensidad que en otras regiones, un proceso urbanizador incontrolado. Con razón puede pensarse que este ataque a la LS es injusto, pues en definitiva de su inaplicación no es responsable el sistema diseñado en la propia Ley. Las críticas van sin embargo más allá. Es el tratamiento concreto de ciertas 
cuestiones por la LS lo que se pone en cuestión, de tal modo que la carencia de planeamiento en la región más parece la consecuencia que la causa de la inadaptación de la legislación estatal al territorio gallego. En concreto, todos los grupos políticos de la Cámara consideran inadecuado el tratamiento del suelo no urbanizable $(y$, en especial, los usos excepcionales del mismo) a Galicia. El uso excepcional de esta categoría de suelo se ha convertido en la práctica de un trámite normal, se señala una y otra vez. Las discrepancias se pondrán de relieve en la manifestación del tratamiento más conveniente a este tipo de suelo en la Ley gallega. Este es, pues, el tema central de la LSG, el suelo no urbanizable o, dicho con otra expresión de la propia LSG, la regulación del medio rural.

Junto a esta insuficiencia de la LS, se especifican otras, como el tratamiento del suelo urbano, el aprovechamiento medio, el suelo urbanizable programado, etc. (42).

Ef resultado final es una Ley que, después de un largo trámite parlamentario -el debate de totalidad del Proyecto es del 16 de febrero de 1984, y es aprobada por el Parlamento gallego el 19 de junio de 1985-, toca numerosas cuestiones del Derecho urbanístico, estableciendo excepciones a la legislación estatal. De forma similar a las otras leyes autonómicas examinadas, regula con mayor precisión aquellos asuntos que se consideran diferenciales e insuficientemente tratados en la legislación estatal. Si en las Leyes de Cataluña y Madrid eran las urbanizaciones de iniciativa particular, aquí lo será el suelo no urbanizable de los núcleos rurales de población.

A diferencia, sin embargo, de las restantes Leyes autonómicas que regulan con profundidad y detalle determinados problemas acuciantes (caso de las urbanizaciones particulares), se advierte en la LSG el deseo de construir un sistema jurídico que se adapte en su totalidad a las características del territorio. De ahí la multiplicidad de las cuestiones tratadas (casi todas las instituciones de la legislación estatal), modulando o matizando ya sea en aspectos marginales o en otros de mayor envergadura la LS. Esto ha determinado el método de análisis seguido en este estudio, en el que predomina el constraste entre la LSG y el Derecho estatal (legislación, doctrina y jurisprudencia), en un afán de ir detectando casuísticamente las excepciones a la legislación estatal. Hay, pues, un hilo conductor en toda la LSG, que se irá revelando a medida que penetremos en su análisis detallado.

Pero esto se hace manteniendo todo el instrumentario conceptual de la legislación estatal —clases de suelo, tipos de planes, etc.hasta el extremo de que en ocasiones se fuerzan los conceptos de la LS en el proceso de adaptación a la ordenación urbana de un

(42) Cfr. en el Diario de Sesiones del Parlamento de Galicia el debate de totalidad del Proyecto de Ley (sesión de 16 de febrero de 1984, pp. 3767, en particular, p. 3786). 
territorio muy diferenciado. Valga como ejemplo la regulación de la edificación en el suelo no urbanizable de los núcleos rurales de población, en que - contra lo que pudiera creerse-la LSG prevé e incluso estimula la consolidación de tales núcleos. Esta contradicción edificación/en suelo no urbanizable deriva en definitiva de la fidelidad de la propia LSG a los conceptos de la legislación estatal -en este caso, la ausencia de los servicios urbanísticos básicos para considerar urbano un núcleo de población-, por lo que, en lugar de crear un nuevo concepto se mantiene el de la LS, pero a la vez forzándole, al darle una significación que en la LS no posee. Este estilo bien perceptible en la LSG (mantener/forzar los conceptos e instituciones de la LS) es el resultado de la opción fundamental por la que se ha inclinado el legislador gallego: el respeto a la legislación general, a la que se "adapta» a las características del territorio gallego. Por ello, es difícil hacer un elogio o una crítica al criterio seguido en la elaboración de la Ley. Quizá se pueda echar de menos la creación de categorías e instituciones nuevas. Se observa un apego excesivo al instrumentario conceptual de la Ley estatal que, por otra parte $y$ de forma inevitable, resulta alterado desde el momento en que la finalidad del legislador gallego no coincide siempre plenamente con la del estatal. Pero, por otra parte, no se nos oculta que una orientación más innovadora hubiera sido arriesgada y de resultados inciertos. Parece en fin más realista la opción de la LSG.

En resumen, la LSG es el resultado de un hecho diferencial de los asentamientos de población en el territorio gallego, profundamente sentido en la Comunidad Autónoma, aliado a la insatisfacción que produce la legislación estatal, más orientada a la ordenación urbana de regiones en las que predominan el proceso de asentamiento en el territorio distinto. Si a esto se añade que el legislador gallego ha sido consciente tanto de la vigencia contrastada de las instituciones de la legislación estatal -que utiliza sistemáticamente-, como de posibles competencias del Estado en el ámbito del urbanismo, tendremos las coordenadas de este texto legal, que respeta la legislación estatal, pero la adapta; que fija excepciones a aquélla en numerosas ocasiones, pero a la vez la declara Derecho supletorio.

\section{D) FUNDAMENTO Y LIMITE DE LAS COMPETENCIAS ESTATALES EN MATERIA DE SUELO}

En un balance final sobre la legislación autonómica dictada a partir de 1981 en materia de urbanismo y de ordenación territorial, es de resaltar esta tendencia a adoptar o adecuar el ordenamiento general a las peculiaridades de cada región. Pero los principios 
básicos en la legislación urbanística estatal se mantienen sin alteración: la clasificación del suelo, el planeamiento previo e incluso las características de los distintos instrumentos de planeamiento, etcétera (43).

\section{El problema, en la doctrina}

Sentado esto, procede preguntarse si estamos realmente ante una sistemática renuncia de los legisladores autonómicos a sustituir plenamente la legislación estatal en esta materia o, por el contrario, bajo tal proceder se esconde, conscientemente o no, la idea de una competencia legislativa estatal que regule los aspectos más importantes del fenómeno urbanístico (44). En este caso la regla de la superioridad sería insuficiente para comprender la relación autonómica/LS en su globalidad.

La dificultad de atribuir competencia exclusiva plena a las Comunidades Autónomas en materia de ordenación del territorio, urbanismo y vivienda, excluyendo toda competencia estatal, ha sido puesta de manifiesto por la doctrina en repetidas ocasiones.

Merece la pena citar la opinión temprana de GARCIA DE ENTERRIA, advirtiendo contra una interpretación literal de la Constitución que aparentemente regionaliza sin más esta materia. Señalaba que la definición del derecho de propiedad así como las competencias del Estado en temas con notorio influjo sobre el territorio no desapoderan totalmente al Estado en la materia. Por lo que entendía que «sería precipitado concluir en un desapoderamiento virtual del Estado en la materia urbanística» (45).

Más tarde, en relación con la ordenación territorial-que constituye, en definitiva, una prolongación «hacia arriba» del propio urbanismo- señala FUENTES BODELÓN una serie de supuestos $y$ argumentos que justifican la intervención estatal en el tema: cuando el planeamiento territorial desborde los ámbitos de una Comunidad Autónoma, cuando se pretenda mediatizar competencias estatales,

(43) Cfr. Parejo Alfonso: Derecho Urbanístico. Instituciones básicas. Ediciones Ciudad Argentina. Mendoza (Argentina). 1986, p. 67: «la dificultad del empeño parece haber inhibido hasta ahora los eventuales propósitos de renovación completa del Ordenamiento jurídico".

(44) Cfr. Muñoz Machado, S.: Derecho Público, cit., p. 412, que habla de dos supuestos de supletoriedad del Derecho estatal respecto al autonómico: cuando la Comunidad Autónoma renuncia obligatoriamente a legislar porque «no puede establecer la disciplina normativa entera de una materia o asunto"; y la renuncia puede ser voluntaria, cuando tal regulación entra dentro de sus facultades, de modo que provoca ella misma el vacío normativo y reclama la norma estatal para llenarlo.

Pero en el primer caso no puede decirse que el Derecho estatal sea supletorio, sino aplicable en primer grado.

(45) Véase GaRcia dE ENTERRIA: «Los principios de la organización del urbanismon en RAP. 87 (1978), pp. 308-309. Como indica el autor, se trata de un comentario hecho inmediatamente después de ser aprobada la Constitución. 
cuando las medidas afecten al interés de toda la Nación; cuando - añade-se precise establecer principios, criterios o bases generales para la ordenación del territorio «las que necesariamente deben acomodarse las actuaciones de las diversas Comunidades, aunque sólo sea para lograr un mínimo de coherencia en la acción administrativa". $Y$ ante lo que considera vaciamiento estatal de competencias en este terreno propone el recurso de una Ley de armonización (46).

Del mismo modo entiende BASSOLS COMA que, a pesar de la omisión constitucional, el Estado ostenta competencias propias sobre el territorio, y debe definir en consecuencia una política de ordenación territorial y adoptar medidas para su coordinación con las Comunidades Autónomas (47). Hay un matiz que diferencia las posturas de ambos autores: mientras para el primero la atribución de competencia exclusiva a las Comunidades Autónomas excluye la legislación estatal por la vía que podríamos denominar ordinaria, teniendo que recurrir a un procedimiento más complejo y forzado como es la Ley de Armonización, BASSOLS parece considerar legítima prima facie la intervención estatal. El instrumento legislativo ya no sería la Ley de Armonización.

Finalmente, PAREJO ALFONSO y LOPEZ RAMÓN coinciden en señalar una serie de competencias estatales que se verían afectadas por la exclusiva de las Comunidades Autónomas sobre la ordenación del territorio y el urbanismo, con la consiguiente legitimación de la intervención estatal. Estos títulos o competencias estatales son: las obras públicas de interés general (y competencia estatal); la planificación de la actividad económica; la legislación sobre el medio ambiente; la defensa del patrimonio cultural, artístico y monumental; así como la formulación del estatuto básico del derecho de propiedad (artítulo 149.1.1. ${ }^{\mathrm{a}}$ de la Constitución) (48).

Particularmente se ha hecho hincapié en utilizar las posibilidades que ofrece la planificación económica estatal para repercutir en la ordenación territorial autonómica (49).

(46) Véase FUENTES BODELON, F.: “El agua y la ordenación del territorion, en / Congreso Nacional de Derecho de Aguas (Murcia, 1982). Murcia, 1984, pp. 324 y ss., 337, 338.

(47) Véase BASSOLS COMA, M.: “Consideraciones sobre el agua y la ordenación del territorio”. En la misma publicación citada en nota anterior, p. 350.

(48) Parejo Alfonso: Derecho Urbanistico, cit. p. 65. LOPEZ Ramón, F.: "Planificación territorials, en RAP, 114, pp. 142 y ss.

(49) Sala Arouer, J. M.: Aspectos juridicos de la ordenación del territorio. Instituto Nacional de Prospectiva. Madrid, 1980, y PAREjo Alfonso, L.: «La ordenación territorial: un reto para el Estado de las Autonomias", en REALA. 226 (1985). Del mismo: “La ordenación administrativa de la ordenación del territorion, en RDU. 105 (1987): La Constitución atribuye a tres niveles de gobierno la formulación de una politica ahorizontaln o integradora; a los Ayuntamientos, la urbanización; a las Comunidades Autónomas, la territorial; al Estado, la planificación económica. Puesto que están imbricadas las tres, propone que la planificación económica estatal ainduzca» las planificaciones sectoriales. 


\section{Una referencia al Derecho alemán: la Federación ostenta competencia legislativa en materia de suelo}

Puede arrojar mucha luz sobre este tema el análisis comparativo del Derecho alemán occidental, ejemplo de un Estado federal asentado. Veamos, en primer lugar, cuál es el modelo de distribución de competencias legislativas entre el Estado federal y los federados: $y$ en segundo término, la situación concreta del urbanismo ( $y$ brevemente de la ordenación del territorio).

Sin perjuicio de las competencias propias de los Estados - de las que luego hablaremos-, hay dos grandes tipos de legislación por razón de la competencia Estado federal/federados: por un lado, la competencia exclusiva de la Federación del artículo 71 de la «Grundgesetz», en las materias del artículo 73. Aqui por principio sólo cabe legislación federal, salvo que el legislador federal expresamente autorice - $y$ en la medida en que lo haga - a los de los Estados miembros para complementar la anterior. El segundo tipo es la legislación concurrente entre Federación/Estados miembros, de acuerdo con los criterios del artículo 72 y en las materias del artículo 74. Aqui tienen éstos campos abiertos para legislar, se les respeta la iniciativa, mientras no lo haga la Federación. En el momento en que ésta dicta una ley en tales materias, la relación ley federal/estatal es muy peculiar: prima la ley federal, por lo que la doctrina califica a este sistema como de concurrencia impropia. Otro efecto característico de este tipo de legislación es el llamado de cierre o exclusión de la legislación estatal que se produce cuando la Ley federal agota el contenido de la regulación, en cuyo caso la estatal decae necesariamente. Lo más frecuente es, sin embargo, que la Ley federal regule los aspectos más importantes, autorizando a la estatal bien a desarrollar lo anterior, o incluso a desarrollar cuestiones próximas no específicamente previstas en la Ley federal. Ahora bien, la legislación federal necesita en este tipo de legislación concurrente una justificacićn especial. Puede decirse que si en el primer caso hay una iniciativa federal sin restricciones (en la legislación federal exclusiva), no sucede así en el segundo. La "Grundgesetz" precisa los requisitos que sirven de detonante a la iniciativa federal, resumidos en la expresión "necesidad de una legislación federal»: si una materia no puede ser eficazmente regulada por los distintos Estados; si afecta a los intereses de otros Estados o daña al conjunto de la nación; si se hace preciso el mantenimiento de la unidad jurídica o económica y, sobre todo, la unidad de las condiciones de vida de la población.

Junto a estos dos supuestos básicos de legislación, el artículo 75 prevé la legislación-marco, sobre la que se discute si es una espe- 
cie de legislación concurrente o constituye en realidad un tipo distinto (50).

En suma, puede resumirse la situación a grandes rasgos como plena iniciativa federal y plena capacidad de regulación en la llamada competencia exclusiva; y limitada iniciativa federal junto a limitada (también, y en la práctica) capacidad legislativa federal en las materias de competencia concurrente.

Pasemos seguidamente a analizar la concreta situación del urbanismo y la ordenacióna territorial en este sistema. En cuanto a la ordenación del territorio, como hemos estudiado dentro lugar (51). fue discutida durante años la posibilidad de que la Federación dictara una Ley, pero al final el Tribunal Constitucional terminó por admitirlo, cuajando en la Ley de Ordenación del Territorio de 8 de abril de 1965 que se ampara en el artículo 75.4 de la Grundgesetz (es un supuesto de Ley-marco) (52).

Tampoco fue fácil discernir las competencias legislativas de la Federación y de los Estados en materia de urbanismo. Tan dudosa era la cuestión que las autoridades federales pidieron un dictamen al Tribunal Constitucional. Este Dictamen de 16 de junio de 1954 ha sentado las bases de la distribución competencial con arreglo a los siguientes criterios: los artículos 74.18 y 75.4 otorgan a la Federación competencia legislativa concurrente en el régimen jurídico del suelo, pero no en todos los casos. Esto es, el Derecho alemán como consecuencia, en buena medida, de las dificultades de la distribución competencial distingue tres planos sucesivos en los que se podría denominar régimen del suelo y edificación: la planificación, la preparación del suelo para la edificación (en líneas generales, lo que entre nosotros se conoce por gestión urbanística) que es una actividad de apoyo a la anterior, y la ordenación de la construcción. Las dos primeras son objeto de legislación concurrente (la legislación federal está compuesta por la Bundesbaugesetz de 23 de junio de 1960 y modificaciones posteriores y la Städtebauförderungsgesetz de 27 de junio de 1971); mientras que el tercer plano es objeto exclusivo

(50) Sobre todo ello puede consultarse el comentario a los artículos 71 y ss. de la Grundgesetz de Ingo v. Münch, Grundgesetz Kommentar, 2 Aufalge. Munich, 1983.

(51) Véase el libro colectivo ya citado de Gallego anabitarte, Menendez Rexach, Diaz Lema Derecho de Aguas en España, pp. 618-9.

(52) Mucho más discutida ha sido la competencia federal para dictar un programa de ordenación del territorio federal (Bundesraumordnungsprogramm) (no ya el marco juridico formal, sino criterios sustantivos de ordenación), mutatis mutandis el posible contenido de nuestro Plan nacional de ordenación, previsto en la LS artículo 7. Una primera iniciativa de la Dieta federal de 1969 fracasó por las razones apuntadas de una competencia federal clara. Pero un Programa de este tipo fue aprobado unos años después, en 1975, en una Conferencia sectorial de Ministros del ramo (sobre esto, véase Friauf, ob. cit. en nota siguiente, p. 534. nota 13). 
de la legislación estatal (sin posibilidad alguna de legislación federal (53).

El criterio material que sirve de frontera a estas tres actividades (fundamentalmente, las dos primeras y la tercera) es un poco impreciso, pero resulta de obligada cita: la planificación mira al conjunto, si un terreno es edificable o no: mientras el tercer plano -ordenación de la construcción- se ocupa de la construcción de la obra individualmente considerada: sus características, sus usos, etc.; es sobre todo un Derecho de policía (54).

Conviene subrayar que la competencia legislativa estatal en este tercer plano arranca del artículo 30 de la «Grundgesetz», disposición fundamental en el conjunto del sistema federal. Establece este artículo una presunción iuris tantum a favor de la competencia de los Estados, siempre que otras disposiciones de la Constitución no la contradigan. En materia de urbanismo, el Tribunal Constitucional consideró competencia legislativa federal (concurrente) en los supuestos señalados, pero no en el tercero. $Y$ si bien es cierto que en las más importantes cuestiones la "Grundgesetz» tiende a atribuir la competencia legislativa bien en exclusiva a la Federación o en concurrencia con los Estados, como se ha visto, o a crear materias compartidas (arts. 91.a y b), eelo no puede hacer olvidar que la "Grundgesetz" crea un Estado que en sus raíces es federal: los Estados miembros ejercen un poder propio y originario (55).

\section{Análisis y comentario de la incidencia de las competencias estatales sobre la ordenación del territorio y urbanismo. Distintos planos.}

A nuestro entender, dentro de la posible incidencia de las competencias estatales sobre la ordenación territorial y el urbanismo hay que distinguir tres planos, que por lo general en la doctrina no aparecen debidamente separados. El primero es el de las obras públicas (estatales o de interés general), y la cuestión aquí radica en determinar si el Estado puede imponer la localización y ejecución de estas obras en contra de lo establecido en la ordenación territorial o la planificación urbanística. El segundo plano es de carácter normativo,

(53) Sobre esto, véase Friauf, K. H.: «Bau-, Boden- und Raumordnungsrecht", en: Besonderes Verwaltungsrecht (ed. por I. v. Münch). 5. edic. Berlín, 1979, pp. 449 y ss.

(54) Ibidem, pp. 449, 492.

(55) Sobre esto, véase el comentario al articulo 30 de la Grundgesetz de I. v. Münch (Grundgesetz Kommentar, citado), quien subraya la tendencia hacia la unidad del conjunto del sistema, lo cual en la práctica devalúa el significado del artículo 30 . En esta cuestión hay una importante quiebra entre el Derecho Constitucional y la realidad constitucional.

En cualquier caso no puede olvidarse la competencia legislativa propia de los Estados, como aparentemnente hace S. MUÑOz MACHADO: Derecho Público de las Comunidades Autónomas, I., cit., p. 405 , al señalar los supuestos de exclusividad y concurrencia. 
y por su contenido, ordenador del territorio. Podría enunciarse así, supuesta la competencia autonómica para ordenar el territorio, ¿cabe la posibilidad de que el Estado dicte algún tipo de directrices de ordenación territorial vinculantes para las Comunidades Autónomas? Por último, el tercer plano -y el que nos interesa especialmente aquí- es si puede el Estado regular el estaturo jurídico del suelo -en base a qué título y con qué límites-. Lo que en definitiva entendemos por régimen del suelo y ordenación urbana.

a) Las obras públicas de interés general: ruptura in extremis del planeamiento vigente, pero no justifican competencia legis/ativva estatal.

Ciertamente, el artículo 149.1 de la Constitución prevé una serie de obras públicas de competencia legislativa del Estado sobre el espacio físico. Dichas obras estatales, en principio, deben ajustarse a lo establecido en los instrumentos de planeamiento en vigor (de ordenación territorial o urbanísticos). Sólo si el Estado estima que la localización y condiciones previstas en el instrumento de planeamiento no son las adecuadas, se plantea el problema de la ruptura de aquéllos.

Esta es la cuestión que se plantea en la conocida STC 56/1986, de 14 de mayo. Ante la negativa de varios Ayuntamientos a otorgar licencia para la construcción de casas-cuartel y el cerramiento de un recinto aduanero, el Consejo de Ministros, en aplicación del artículo 180 de la LS, autorizó excepcionalmente las obras con la consiguiente quiebra de las facultades urbanísticas locales. El Tribunal Constitucional estimó ajustada a la Constitución la decisión del Consejo de Ministros.

Nótese bien que eso no implica ni el otorgamiento de facultades legislativas ni de carácter planificador al Estado. Es cierto que, si se permite esta ruptura de la planificación autonómica o municipal, éstas resultan evidentemente condicionadas por el ejercicio de la competencia estatal. Pero no debe exagerarse este efecto, y entender que la competencia del Estado sobre las obras de interés general lleva consigo la de planificar territorialmente su localización, como una especie de planificación territorial sectoriada. En otras palabras, la competencia del Estado sobre las obras de interés general no le otorga una competencia de tipo planificador del territorio (56).

Por lo demás, no se debe sobrevalorar el mecanismo excepcional del artículo 180 de la LS. Como señala el propio Tribunal Constitucional en la sentencia citada 56/1986 (FJ 5), se trata de una norma preconstitucional $y$, por tanto, no adaptada a los esquemas de

(56) Como parece entender LOPEZ RAMON, ob. cit., p. 144. 
relación del Estado autonómico. Como hemos expuesto en otro lugar (57), la planificación territorial no puede tener en el Estado autonómico una significación jerárquica, sino de integración o armonización de los distintos proyectos en juego. Esta función coordinadora la asumen las Comunidades Autónomas. Sólo cuando se haga imposible el ajuste de las distintas competencias, es procedente plantearse la ruptura del planeamiento a través de la obra de interés general.

Esta ruptura se justifica en el interés de orden superior que compete al Estado frente a las organizaciones territoriales inferiores (58). Lo cual no es exclusivo de nuestro sistema. En el federalismo alemán se ha aceptado que las obras de la Federación o de los Estados sean ejecutadas, aun en caso de disconformidad con el planeamiento local. Con ello se asegura el ejercicico de las competencias sectoriales, en sectores como los telégrafos, vías de ferrocarril, carreteras, obras hidráulicas, etc., y, por supuesto, una vez que se han agotado los mecanismos de articulación. Como contrapartida, el Estado o la Federación están obligados a indemnizar a la Corporación local los gastos para la confección del Plan de ordenación modificado (59).

Como conclusión, cabe afirmar que la competencia estatal para ejecutar obras de interés general no supone el otorgamiento de una competencia de ordenación territorial añadida implicitamente (60).

(57) En El Derecho de Aguas en España, cit., pp. 625 y ss. En el mismo sentido Parejo AlfONSO, L: La organización administrativa de la ordenación del territorio, cit., p. 37: la planificación territorial debe entenderse como un procedimiento de coordinación de actuaciones y compatibilización de ámbitos competenciales

(58) Por ello no es acertada la afirmación de PAREJO ALFOnSO: «La ordenación territorial: un reto para el Estado de las Autonomias», en Revista de estudios de la Administración local y autonómica, número 226, p. 216, de que todas las competencias son iguales. No debe al menos entenderse en el sentido de que el el ejercicio de una impida el de otras (que corresponden a un interés superior).

Por lo demás, no creemos que esta ruptura del planeamiento por la obra estatal se justifique en la prevalencia del Derecho estatal (art. 149.3 de la Constitución), como afirma LOPEZ RAMON: $o b$. cit., p. 144. Aqui se trata de un proyecto de obra (concreto), no de Derecho estatal.

(59) Cfr. mi aportación a: El Derecho de Aguas en España, cit., pp. 625, 627.

En un estudio para el Ministerio de Obras Públicas y Urbanismo (inédito) de Alfredo Gallego ANABITARTE, que me ha facilitado, se tratan estos mecanismos de imposición de un proyecto de obra, aun en contra del planeamiento vigente, en el Derecho alemán (Planfeststellungsverfahren). Ello permite un amplio margen de maniobra a la Federación en la ejecución de la legislación sectorial.

Es evidente que en el futuro el rudimentario sistema del articulo 180 de la LS tendrá que evolucionar en forma parecida a la vigente en el Derecho alemán.

(60) La posible aplicación de la doctrina de los "poderes implícitos" ha sido tratada de forma muy cautelosa por el Tribunal Constitucional en dos sentencias. En la STC $66 / 1985$, de 23 de mayo (FJ 55) no entra a valorar el argumento de los recurrentes de la existencia de dichos poderes implícitos. En la STC 56/1986, de 13 de mayo, los magistrados que formulan el voto particular entienden que la sentencia acoge la doctrina de los «poderes implícitos» por aceptar que ula titularidad de una determinada competencia faculta para realizar en otros campos, en materias respecto de las que no se posee competencia alguna, cuantos actos resulten necesarios 
Que, de acuerdo con nuestro sistema de distribución competencial Estado/Comunidades Autónomas, el número de aquellas obras de interés general sea muy elevado, no altera los términos del problema. No es una cuestión de cantidad, sino de cualidad. La planificación territorial autonómica debe integrar las obras estatales. Cuando no sea posible esta articulación, la obra estatal rompe el planeamiento establecido. Que esto suceda en unos pocos casos o en muchos - dado el elevado número de obras que corresponden a la compentencia estatal- es indiferente: habrá que poner en marcha los mecanismos de articulación con más frencuencia, pero eso no otorga al Estado una competencia de ordenación territorial, ni en la planificación ni en la legislación.

\section{b) ¿Tiene el Estado en algún caso competencias de planificación territorial?}

La siguiente cuestión que se plantea es si puede el Estado dictar algún tipo de directrices de ordenación territorial vinculantes para las Comunidades Autónomas. Ya hemos señalado que hay autores que así lo han estimado sin reparo alguno. Concretamente, FUENTES BODELON (véase supra) indica varios supuestos en que se debe reconocer al Estado competencia para ordenar el territorio, $y$ habla de principios, bases generales o criterios para lograr un mínimo de coherencia en la acción administrativa. O el propio BASSOLS COMA, citado igualmente supra.

Esta vía de defender abiertamente una competencia estatal de ordenación territorial no ha tenido mucho eco en la doctrina. Más bien, la opinión generalizada se ha inclinado por acudir a una segura competencia estatal (la planificación de la economía), que vendría así a condicionar o limitar la ordenación territorial autonómica (cfr. lo dicho anteriormente al respecto, en concreto la opinión de PAREJO ALFONSO).

Ahora bien, salvo que se desnaturalice, es difícil que la planificación económica pueda servir de cauce para orientar las distintas actividades en el territorio. $Y$ de hacerlo, estaría invadiendo la competencia autonómica.

Puede servir de referencia útil en este punto el Derecho alemán, en el que no sin dificultades como se ha visto supra, se han aprobado

\footnotetext{
para el ejercicio de la competencia propian. Por lo que, según ellos, es correcto el fallo de la sentencia, aunque no su razonamiento.

A nuestro juicio, el problema que se suscita en esta Sentencia no debe situarse en la órbita de la doctrina de supuestos "poderes implícitos" del Estado, sino del juego de la legislación sectorial y la planificación urbanística/territorial. Por lo demás, al menos en lo que se refiere al plano legislativo, nuestro sistema constitucional no precisa acudir a la doctrina de los "poderese implicitos", desde el momento en que la regla del articulo 149.1.1. " otorga al Estado facultades legislativas en cualquıi. malterla, aunque en condiciones tasadas (sobre esto, véase infra).
} 
unos «principios» de ordenación de todo el territorio federal. Pero curiosamente nuestra Constitución no contempla ninguna atribución específica de competencia al Estado en este terreno, frente a lo que sucede en el Derecho alemán.

La situación es contradictoria: un sistema como el autonómico que detiene las competencias de las Comunidades Autónomas allí donde se encuentra con el interés general (lo que es común a dos o más Comunidades Autónomas), en una materia concreta-ordenación del territorio y urbanismo- se produce una entrega en bloque al ámbito competencial autonómico.

Interpretando la competencia sobre ordenación territorial y urbanismo de acuerdo con las pautas globales de distribución competencial, hay dos situaciones en que no se debe excluir tajantemente y a priori una competencia estatal para ordenar sustantivamente el territorio. A la primera nos hemos referido en otro lugar (61). Se trata de aquellos casos en que una región natural desborde el marco físico de una Comunidad Autónoma, y que sea conveniente la formulación de un plan territorial. Aunque probablemente la vía más acorde a la Constitución sea la de un Convenio entre las Comunidades Autónomas afectadas, no se puede descartar que en este caso el Estado sea competente, puesto que la competencia estatal empieza allí donde se agota el interés propio de la Comunidad Autónoma. Cuando un determinado asunto o materia afecta a más de una Comunidad Autónoma, salta automáticamente el resorte de la competencia estatal (por ser un tema de interés general) (62).

La segunda situación vendría dada por la necesidad de armonizar ordenaciones territoriales de dos o más Comunidades Autónomas, que sean contradictorias entre sí. Podrá el Estado, dado el caso, aprobar ciertas directrices o principios de ordenación territorial, sea para el conjunto del territorio o para partes del mismo, siempre que se limitara a enunciar principios genéricos con la finalidad coordinadora apuntada.

c) El fundamento de la competencia legis/ativa del Estado: artículo 149.1.1. ${ }^{a}$ de la Constitución. Sus límites.

El tercer plano de la incidencia estatal en la competencia autonómica es la posibilidad de que el Estado regule el estatuto jurídico del suelo. Ya hemos visto que las actuaciones estatales anteriores - obras públicas $y$, a lo sumo, unos principios de ordenación territorial - no justifican por sí mismas la compentencia legislativa

(61) En: El Derecho de Aguas en España, cit.. pp. 617-618.

(62) El supuesto planteado no es imaginario. En la publicación citada en nota anterior, se indicaba el Decreto de 23 de mayo de 1980, que acordó la formación de un Plan Director Territorial para la Sierra de Gredos, abarcando municipios de las provincias de Avila y Cáceres. 
del Estado que se trata en este momento. Las razones que apoyan, en su caso, aquellas competencias del Estado no son válidas para asegurar que éste pueda dictar una regulación o régimen del suelo.

El fundamento de la legislación estatal sólo puede radicar en el artículo 149.1.1. a de la Constitución: la garantía de la igualdad de los españoles en las condiciones básicas del ejercicio de los derechos, en este caso el de propiedad (63).

Debe hacerse, sin embargo; una advertencia. Se descarta que el origen de la competencia estàtal para legislar en materia de suelo sea la atribución al Estado en el artículo 149.1.8. ${ }^{\text {a }}$ de la legislación civil, con carácter exclusivo, salvo los Derechos forales o especiales. No se trata de que, por tratarse de una materia típicamente civil -la propiedad-, ostente el Estado competencia legislativa. Por este camino el margen de la legislación autonómica se reduciría extraordinariamente, porque son innumerables las posibilidades de afectar al derecho la propiedad a través del ejercicio de sus competencias.

El tema ha sido tocado en la STC 37/1987, de 26 de marzo (Ley de reforma agraria andaluza). En el fundamento jurídico 8 el Tribunal se enfrenta a este argumento de la parte recurrente; y estima que no sólo la legislación civil, sino también la administrativa fijan el contenido del Derecho de propiedad en cada tipo de bienes objeto de intervención administrativa, pues en definitiva dicho contenido es una amalgama de los intereses individuales y del interés colectivo, expresión de la función social de la propiedad. La consecuencia que extrae el Tribunal, con expresa referencia a la legislación urbanística, es que la legislación agraria - administrativa- se superpone a la civil propiamente dicha: ambas conjuntamente resumen el contenido del Derecho de propiedad en los distintos bienes.

Existen varios estudios sobre el principio de igualdad en la Constitución (64), aunque específicamente dedicado al análisis del artículo 149.1.1. a sólo un artículo de CARRO FERNANDEZ-VALMAYOR del que nos ocuparemos ampliamente a continuación (65).

Nuestra Constitución, en efecto, ha introducido esta competencia, que toma, sin lugar a dudas, del artículo 72.2 de la Ley Fundamental alemana. Dispone éste que en las materias de competencia concu-

(63) La cita de este precepto como fundamento de competencias estatales en materia de suelo es común en la doctrina. Véanse TOMAS-RAmOn Fernandez: Manual de Derecho Urbanistico.

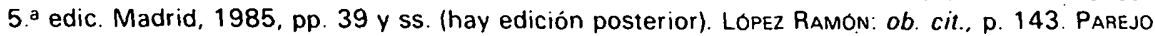
Alfonso, Derecho Urbanístico, cit., 65. Aunque unido a las otras competencias estatales que, a nuestro juicio, no justifican facultades legislativas del Estado.

(64) Baste citar el libro de SUAY RINCON, J.: El principio de igualdad en la justicia constitucional. IEAL. Madrid, 1985. O los artículos de ALonso GARCIA, E.: «El principio de igualdad del artículo 14 de la Constitución Española», en RAP. 101-102, vol. I, pp. 21 y ss.; y de BAÑo LEON, J. M.: «La igualdad como derecho público subjetivo», en RAP, 114 (1987), pp. 179 y ss.

(65) Carro Fernandez-Valmayor, J. L.: «Contenido y alcance de la competencia del Estado definida en el artículo 149.1.1. ' de la Constitución", en Revista Española de Derecho constitucional (enero-abril 1981), pp. 133 y ss. 
rrente -sobre cuyo significado ya nos hemos extendido supra, como materias de iniciativa legislativa estatal en principio- puede legislar la Federación cuando se den varias circunstancias. En este momento nos interesa fundamentalmente la prevista en el apartado 72.2.3.o. cuando se trate de garantizar la unidad jurídica o económica, en especial la garantía de la unidad de las condiciones de vida de la población.

El artículo 149.1.1. ${ }^{\text {a }}$ de nuestra Constitución está inspirado en el precepto señalado de la Constitución alemana, pero hay una diferencia muy importante que no debe ser pasada por alto: mientras en la "Grundgesetz» alemana esa competencia legislativa federal se pone en marcha en las materias tasadas de competencia concurrente -que son, desde luego, muchas y muy amplias (art. 74) - , en nuestro caso no hay una frontera de tipo material a la legislación estatal. La competencia del artículo 149.1.1. ${ }^{\text {a }}$ puede ejercitarse sobre cualquier tipo de competencias autonómicas, aunque va de suyo que esa necesidad de igualdad básica se hará más precisa en las competencias exclusivas de las Comunidades Autónomas.

Así lo entiende igualmente CARRo en el artículo citado en nota anterior: el artículo 149.1.1. ${ }^{\text {a }}$ afecta a todos los derechos y deberes, tanto fundamentales como ordinarios (66). Con razón estima que esta garantía de igualdad básica en manos del Estado se concibe de forma beligerante frente a las Comunidades Autonomas (67). E incluso Ilega a citar el ámbito urbanístico como posible campo de aplicación de dicho precepto (68).

Hay, sin embargo, algunos puntos del análisis de CARRo que deben ser corregidos, a la luz de la jurisprudencia posterior del Tribunal Constitucional sobre todo. En primer término, identifica las "Condiciones básicas» del artículo 149.1.1. a con el "contenido esencial» del artículo 53.1 de la Constitución (69). A nuestro entender, son cosas distintas, y obedecen a problemas dispares. El respeto al contenido esencial obliga a cualquier legislador - estatal o autonómico- a no limitar de tal modo los derechos previstos en la Constitución que resulten desnaturalizados. Es un mandato constitucional a los distintos legisladores. Por el contrario, el artículo 149.1.1. ${ }^{\text {a }}$ trata de asegurar un mínimo común denominador frente a la legislación autonómica. Ambos preceptos obedecen a una funcionalidad distinta, y no tienen por qué coincidir. Por ejemplo, es posible que varias Leyes de Comunidades Autónomas respeten el contenido esencial, pero sean gravemente discrepantes entre sí: entra en

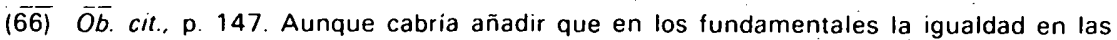
condiciones básicas se produce automáticamente, en virtud de la Ley orgánica que los regula.

(67) Ibidem, p. 146.

(68) Ibidem, pp. 148-149

(69) Ibidem, pp. 148-149. 
funcionamiento el artículo 149.1.1. ${ }^{\text {a }}$, pero no el 53.1 de la Constitución.

El segundo término, estima CARRo que la intervención normativa estatal que propicia el artículo 149.1.1. ${ }^{\text {a }}$ puede ser posterior a la legislación autonómica, o anterior y espontánea. En el primer caso, sería una Ley-medida; en el segundo, una Ley general. En ambos, el rango sería de ley orgánica, por regular un derecho fundamental: la igualdad (70). Por último, señala que estas leyes no coinciden con la Ley de Armonización del artículo 150.3 de la Constitución (71). Se trataria, por tanto, de un tipo nuevo de ley estatal, no expresamente previsto dentro de los distintos supuestos que regula la Constitución.

Discrepamos de esta opinión en dos puntos: ante todo, la Ley del artículo 149.1.1. ${ }^{\mathrm{a}}$ no tiene por qué ser orgánica. Como ha dicho el Tribunal Constitucional, el artículo 14 de la Constitución (derecho de igualdad) está expresamente excluido de las materias reservadas a la Ley Orgánica en el artículo 81.1 de la Constitución [STC de 5 de agosto de 1983 - LOAPA-, FJ 2.a)]. Es más, como se ha indicado, difícilmente la ley que derive del artículo 149.1.1. a será orgánica, porque este precepto asegura lo que por otros medios no se puede alcanzar. Y es evidente que al regular por Ley orgánica el Estado los Derechos Fundamentales sin necesidad de recurrir al artículo 149.1.1. ${ }^{a}$, está estableciendo las condiciones básicas y otras que no lo son.

Más interés tiene, no obstante, señalar que el rechazo de CARRO a la Ley de Armonización no está justificado. Más bien creemos que el artículo 149.1.1. ${ }^{a}$ no crea ningún instrumento normativo nuevo, y encarece, por tanto, la garantía de la igualdad en las condiciones básicas a los ordinarios previstos en la Constitución, entre los que se cuenta la Ley de Armonización.

En resumen, estimamos que la Ley de Armonización del artículo 150.3 de la Constitución es un medio adecuado a la finalidad del artículo 149.1.1. ${ }^{\text {a }}$ aunque esto no supone que todas las virtualidades de este tipo de ley se agoten en el cumplimiento de dicho precepto.

A propósito de la Ley de Armonización, el Tribunal Constitucional en la sentencia antes citada de 5 de agosto de 1983 - FJ 3.b)-, después de señalar su carácter complementario de los otros mecanismos constitucionales, extiende su aplicación tanto a las competencias exclusivas de las Comunidades Autónomas (que será el supuesto normal), como a las compartidas. Pero no se pronuncia el Tribunal sobre si la armonización debe ser siempre posterior a la legislación autonómica (como parece deducirse del mismo término), o por el contrario se puede anticipar a aquélla. En la doctrina, GARRIDO

(70) Ob. cit., p. 150

(71) Ibidem, p. 152. 
FALLA entiende que caben las dos posibilidades (72), que probablemente sea lo más acertado.

En definitiva, a nuestro juicio, la competencia legislativa del Estado en materia del suelo y ordenación urbana sólo puede dimanar del artículo 149.1.1. ${ }^{a}$ de la Constitución, siendo el instrumento legislativo adecuado la Ley de Armonización. El contenido de dicha ley se debe centrar, ante todo, en los derechos y deberes de los propietarios en los distintos tipos de suelo, con una regulación mínima igual para todo el territorio nacional; así como de los instrumentos de planeamiento y gestión que aseguren un status básico igual de los ciudadanos frente al poder público.

El Tribunal Constitucional ha empleado el argumento del artículo

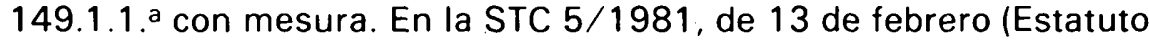
de Centros Escolares) (FFJJ 22 y 27), lo utiliza en relación con otros preceptos de la Constitución que atribuyen al Estado competencia en materia de enseñanza, impidiendo que las Comunidades Autónomas entren a regular tales cuestiones. Probablemente, el derecho fundamental en juego - la educación- ha llevado al Tribunal a una interpretación amplia del precepto.

En la STC 37/1987, de 26 de marzo (FJ 9), toca nuevamente el tema del artículo 149.1.1. ${ }^{a}$. Advierte que este precepto no puede servir de excusa para vaciar de competencias a las Comunidades Autónomas, pero reconoce que en virtud del mismo puede el Estado «atraer a su ámbito competencial una potestad normativa en relación con la función social de la propiedad sobre cualquier tipo de bienes y en virtud de cualesquiera intereses de carácter público, aun aquellos cuya definición y gestión no le está ya encomendada». Está claro, pues, que la regla del artículo 149.1.1. a no conoce límites en las competencias de las Comunidades Autónomas. El límite radica en si se estiman o no lesionadas las condiciones básicas del ejercicio de los derechos por los ciudadanos o sus posiciones jurídicas fundamentales. En el caso concreto de la sentencia el Tribunal entiende que no se produce tal extralimitación por respetar la Ley de reforma agraria andaluza los principios o bases que, en relación con la función social de la propiedad agraria, se deducen de la legislación vigente, tratándose, en muchos casos, de simples traslaciones de normas estatales.

De ello se sigue que, si el Estado estima que se producen graves desigualdades en un ámbito competencial de las Comunidades Autónomas como el urbanístico, o incluso con el fin de evitar que se lleguen a producir, el artículo 149.1.1. ${ }^{\text {a }}$ fundamentalmente a través de la Ley de Armonización le otorga la cobertura constitucional

(72) En: «El desarrollo legislativo de las normas básicas...», cit., p. 31. 
precisa para obligar a las Comunidades Autónomas a respetar ese mínimo común denominador en el ejercicio de los derechos y deberes por todos los ciudadanos.

\section{Conclusión: limitada competencia legislativa estatal. Sentido de la «adaptación»de la LSG}

En conclusión, se hace patente que una interpretación rigurosa de la competencia exclusiva de las Comunidades Autónomas en materia de urbanismo - desplazando absolutamente la legislación estatalsería de dudosa constitucionalidad. Que en un sistema federal se ha impuesto el recurso a.la legislación federal - salvo el supuesto ya señalado-, debe servir de recordatorio para evitar una interpretación imprudente de nuestra Constitución, cosa que afortunadamente no se ha hecho, como lo demuestran las leyes autonómicas mencionadas.

En una sintesis final de este capítulo se puede decir ya que el concepto «adaptación» de la LSG (como el muy próximo de «adecuación» de la Ley catalana de 9 de enero de 1984) revela el trasfondo de varios hechos distintos, pero que concurren al unísono: por un lado las particularidades geográficas o de otro orden de las distintas regiones, que obligan a adoptar disposiciones urbanísticas especiales en su ámbito territorial; por otro, el marco competencial de la Constitución de 1978 - en apariencia, muy generosa al atribuir competencia exclusiva a las Comunidades Autónomas - ciñe los contornos de la legislación autonómica a través de la legislación general. Es el Derecho de propiedad (urbana o camino de serlo) lo que está en juego, así como el principio del artículo $149.1 .1 .^{\text {a }}$ de la Constitución: garantía del respeto a la igualdad de los españoles en el ejercicio de sus derechos.

En el proceso de elaboración de la LSG se encuentran repetidamente alusiones a la comapetencia legislativa estatal en el sentido aquí indicado. Así, por ejemplo, en la discusión en el Pleno de la Cámara del artículo 18 del Proyecto de Ley un diputado advertirá que «en cuanto al suelo urbano, el proyecto aporta pequeñas novedades, puesto que por las posibles implicaciones sobre el Derecho de propiedad, común a todo Estado, no se considera prudente profundizar en esta cuestión» (73).

En definitiva, bajo la remisión al Derecho estatal, en todo lo que no sea objeto de excepción, no hay, por tanto, un renuncia voluntaria de la Comunidad Autónoma a hacer uso de su competencia legislativa exclusiva, sino más bien obligada por la existencia de competencias estatales en esta materia.

(73) Palabras del señor Pia Martinez (Diario de sesiones: Sesión plenaria núm. 125, jueves, 18 de julio de 1985). 
En todo caso, en materia de urbanismo, la atribución de una competencia exclusiva a las Comunidades Autónomas permite a éstas establecer excepciones al Derecho general, salvo en las cuestiones que se consideren de competencia estatal. $O$, en otras palabras, el principio de prevalencia a favor del Derecho estatal del artículo 149.3 de la Constitución juega en el caso de las competencias exclusivas de las Comunidades Autónomas justamente al revés: a favor de la legislación autonómica. Quizá radique aquí en este antagonismo prevalencia del Derecho estatal/prevalencia del Derecho autonómico la clave para comprender la relación entre ambas legislaciones: primacía del Derecho estatal como criterio general que se concretará en varios supuestos (legislación básica, etc.), salvo en las competencias exclusivas de las Comunidades Autónomas. Prevalencia del Derecho autonómico en este último caso, lo cual permite crear bolsas de Derecho autonómico, pero no necesariamente desplazar en su totalidad el Derecho estatal. El límite de esta prevalencia autonómica surge, sin embargo, cuando el Derecho autonómico alcanza competencias estatales.

La comprensión del fundamento constitucional de la LSG determina forzosamente el criterio metodológico seguido en el análisis de la Ley, que se resume en el sistemático contraste y diálogo con la legislación estatal. El resultado final es un bloque normativo, el Derecho Urbanístico de Galicia, perfectamente ensamblado.

Por lo demás, las innovaciones de esta Ley -así como de las restantes Leyes autonómicas citadas - deben ser comtempladas no sólo desde la óptica competencial -en qué medida contradicen la legislación estatal-, sino también con un criterio positivo de colaboración y diálogo entre los distintos "legisladores», en un constante proceso en el que por prudencia es lógico que sean las Comunidades Autónomas las primeras en abordar nuevas soluciones legislativas. Sólo cuando estén debidamente contrastadas, puede tener sentido su incorporación al Derecho general. 